tability of the variables affecting the numerical productivity of the sows. The herd of origin accounted for about 5 per cent of the variance of litter size and for 30 to 55 per cent of that of the lactation length. Estimations of the repeatability of the litter size varied from 0.13 to 0.17 those of the other variables were less homogenous.

Within-litter linear correlations between variables showed that the litter size was independent of the weaning-fertilization interval, but tended to decrease with lactation length. The curves representative of the polynomial regression equations accounting for the variations of the litter size at weaning in terms of litter size at birth show that the latter variable increases up to a maximum of 17 piglets born for Large White and French Landrace, 15 for Pietrain and 6 for Belgian Landrace. However, a piglet has a maximum of chances for surviving until weaning when born in a litter whose size varies from 6 to 9 in the first two breeds and from 5 to 8 in Belgian Landrace.

\title{
Heritability of defective nipples in gilts
}

\author{
M. MOLENAT (1) et B. THIBAULT ( $\left.{ }^{2}\right)$ \\ (') Station de Génétique quantitative et appliquée \\ I.N.R.A.-C.N.R.Z., $783.5^{\circ}$ Jouy-en-Josas (France) \\ (2) École Nationale Vétérinaive, $9470 \mathrm{~T}$ Maisons-Alfort (France)
}

Teats of 892 gilts from is sires and 77 dams were observed. It appeared that defective nipples were located along the mammae line with higher frequency in the middle of line. When a gilt had several defective nipples they were arranged in groups.

Heritability of that abnormality was calculated by gilt/dam regression and by analysis of variance. We found the same heritability for absolute number and per cent of defective nipples. The heritability varied from 0.30 to 0.65 . We conclude that selection against that abnormality can be efficient.

\section{Genetical analysis of sperm production in the young large white boar : preliminary results}

\author{
M. COUROT (1) et C. LEGAULT (2) \\ (') Physiologie de la Reproduction, I.N.R.A., 37380 Nouzilly (France) \\ (2) Génétique quantitative et appliquée \\ C.N.R.Z.-I.N.R.A., 78350 Jouy-en-Josas (France)
}

Testicular and epididymal weight as well as gonadal and extragonadal sperm reserves have becn analysed in 95 Large White boars trom 8 difterent paternal lines and 53 litters, slaughtered at a mean body weight of $103.6 \pm 16.2 \mathrm{~kg}$ and a mean age of $195.4 \pm 14.2 \mathrm{~d}$ following performance testing. All the data have been adjusted for a constant body weight of $103.6 \mathrm{~kg}$.

The characteristics of organ weights and sperm reserves were independant of growth rate botween 30 and $80 \mathrm{~kg}$ and of the dorsal fat thickness at $80 \mathrm{~kg}$. There was a large range of variation between the means per paternal lines: 22 and 23 per cent testicular and epididymal weights, 37 and 35 per cent for the gonadal and extragonadal sperm reserves. A strong correlation was observed between sperm reserves and the weight of the corresponding organs. All these parameters seem to be under genetic control, however the effect of litter size is more important than the paternal effect. 